\title{
Engineering embedded metal nanoparticles with ion beam technology
}

\author{
Feng Ren • Xiang Heng Xiao • Guang Xu Cai • \\ Jian Bo Wang • Chang Zhong Jiang
}

Received: 7 January 2009 / Accepted: 3 March 2009 / Published online: 26 March 2009

(C) The Author(s) 2009. This article is published with open access at Springerlink.com

\begin{abstract}
In this paper, we summarize our recent results of study on how to engineer the embedded metal nanoparticles in silica by ion implantation and ion irradiation technologies, including controlling the size, distribution and morphology of nanoparticles. The optical properties of the tailored nanoparticle composites are studied. Thermal annealing, electron beam irradiation, and chemical erosion are used to study the stability of these embedded nanoparticles by ex situ or in situ transmission electron microscopy observation.
\end{abstract}

PACS 61.46.Df $\cdot$ 61.72.U- $\cdot$ 61.80.Jh $\cdot$ 61.80.Fe

\section{Introduction}

The surface plasmon resonance (SPR) of metal nanoparticles (NPs) has attracted a considerable attention for many years due to its wide applications, including biomarkers for molecular imaging [1], optical switches [2], controlling drug delivery [3], photothermal cancer treatment [4], waveguider [5], as well as enhancing the photoluminescence of semi-

F. Ren $(\bowtie) \cdot$ X.H. Xiao · G.X. Cai · J.B. Wang · C.Z. Jiang Key Laboratory of Acoustic and Photonic Materials and Devices of Ministry of Education, and Department of Physics, Wuhan University, Wuhan 430072, China

e-mail: FRen@lbl.gov

C.Z. Jiang $(\varangle)$

e-mail: czjiang@whu.edu.cn

F. Ren

Lawrence Berkeley National Laboratory, Berkeley, CA 94720, USA conductor materials and devices [6]. The optical properties of metal NPs determined by the surface electric field of NPs greatly depend on their size, distribution and morphology. Therefore, for the actual application of NP composites, a careful control of the size, distribution and morphology of NPs has to be achieved so that the NP properties can be tuned. Many methods, like chemical synthesis technique, have been used to produce NPs with good controlled size and morphology [7]. Despite of their great success, these methods, however, are not fully compatible with current wafer fabrication technology and still needed to improve the stability of NPs. Ion beam technology (ion implantation or ion irradiation) has been used for over three decades to fabricate NPs in dielectric materials and provides a versatile technique compatible with industrial device fabrication by carefully controlling ion energy, mass, fluence, current density, etc. $[8,9]$. The embedded NPs are very stable because they are well separated from surrounding environment and protected by the substrate. This is very important for the actual application of NPs to NP-related devices. One problem, associated with the synthesis of NPs using ion implantation, is the hardly controlled nucleation and growth processes resulting in a broad spatial and size distribution of NPs and reducing the possibility of practical applications [10].

In this paper, we summarize our recent results of study on how to engineer the embedded metal nanoparticles in silica by ion implantation and ion irradiation technologies. We introduce how to control the size, distribution and morphology of Ag NPs to tailor the optical properties of the NP composites. We also study the stability and the behavior of these NPs under thermal annealing, electron beam irradiation and chemical erosion. 


\section{Controlling the size and distribution of nanoparticles}

Many ion beam methods have been used to tailor the size and distribution of NPs. The methods can be divided into mainly two ways. One is post-implantation treatment, such as annealing in different atmospheres [10] or ion irradiation. The embedded spherical NPs can be transfer to rodlike shape [11, 12] or caused alignment of NP [13] by swift ion irradiation, which is leading to the anisotropic surface plasmon resonance of NPs. Although various models, like Coulomb explosion [14], viscoelastic model [15], ion hammering effect [16] and thermal spike model [17], are used as possible mechanisms to explain the change, the exact mechanisms responsible for NC shape transformation still need to be further investigated. Ion irradiation also can be used to tailor the size and spatial distribution of the embedded NPs. Rizza et al. [18] used $4 \mathrm{MeV} \mathrm{Au}{ }^{+}$ions to irradiate Au NPs, the NPs are resolved into more uniform small ones. Similar phenomenon was observed in the experiment of irradiation of Au NPs by 2.3 MeV Sn ions [19].

Another way to tailor NPs is precise choice of implantation parameters, like ion energy, current density, fluence, substrate temperature and implantation sequence. Ramaswamy et al. [20] perform multiple-step ion implantation and intermediate annealing method to control the size and size distribution of Au NPs by isolating the nucleating and growth of NPs. Figure 1(a) shows the cross-sectional TEM images of $200 \mathrm{keV}, 5 \times 10^{16} \mathrm{Ag}^{+}$ions $/ \mathrm{cm}^{2}$ implanted sample into silica at current density of $2.5 \mu \mathrm{A} / \mathrm{cm}^{2}$. Ag NPs are distributed in the same depth, which is quite different from the well-known Gauss distribution for ion implantation at low current density for the same fluence [21]. Under high current density implantation, more heat will be deposited in the sample in short time, which is increasing the diffusion of silver atoms. Therefore, the implanted Ag ions trend to aggregate to larger NPs. The $200 \mathrm{keV}, 5 \times 10^{16}$ $\mathrm{Ag}^{+}$ions $/ \mathrm{cm}^{2}$ implanted sample was further implanted by $110 \mathrm{keV} \mathrm{Cu}^{+}$ions to the fluence of $5 \times 10^{16} \mathrm{ions} / \mathrm{cm}^{2}$. The energy for $\mathrm{Cu}^{+}$ions was selected to get closed-ion distribution of two elements so that the energy of $\mathrm{Cu}^{+}$ions can be deposited in the $\mathrm{Ag}^{+}$ions implanted region. Figure 1(b) is the cross-sectional TEM image of the $\mathrm{Ag} / \mathrm{Cu}$ sequentially implanted sample. By analyzing the NPs in the TEM image, we find that the average size of NPs increases from $24 \pm 5.9 \mathrm{~nm}$ in $\mathrm{Ag}$ implanted sample to $31 \pm 5.4 \mathrm{~nm}$, while the distribution of Ag NPs does not change. The increase of NP size is due to the irradiation-enhanced diffusion of $\mathrm{Ag}$ atoms during $\mathrm{Cu}^{+}$ion implantation [22,23]. The energy from implanted $\mathrm{Cu}^{+}$ions deposits in the implanted region of $\mathrm{Ag}$ ions, which is increasing the substrate temperature and enhancing the diffusion of Ag atoms dispersed in silica. Therefore, the large Ag NPs absorbs dispersed Ag atoms to grow. By selecting suitable ion implantation condition,
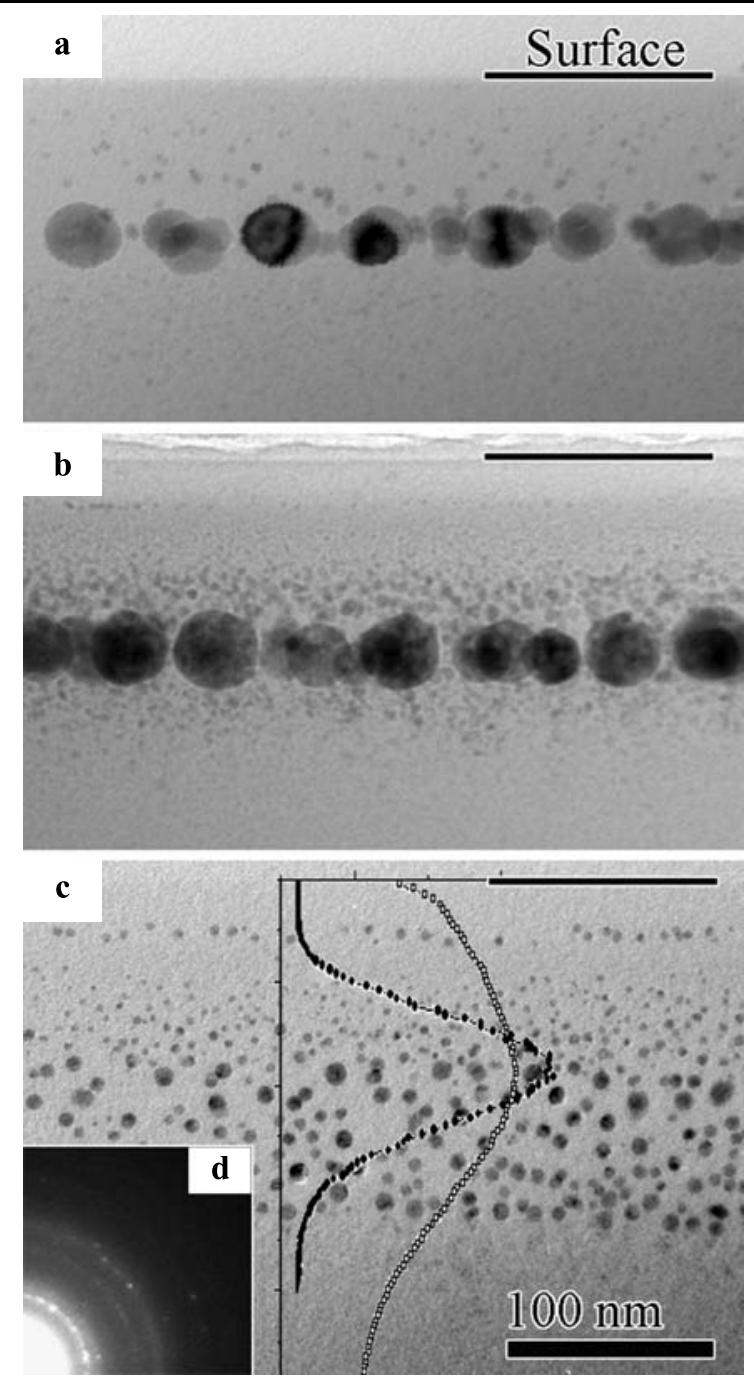

Fig. 1 Cross-sectional TEM images of the $200 \mathrm{keV}, 5 \times 10^{16}$ $\mathrm{Ag}^{+}$ions $/ \mathrm{cm}^{2}$ implanted sample (a); the $200 \mathrm{keV}, 5 \times 10^{16} \mathrm{Ag}^{+}$ ions $/ \mathrm{cm}^{2}, 110 \mathrm{keV}, 5 \times 10^{16} \mathrm{Cu}^{+}$ions $/ \mathrm{cm}^{2}$ sequentially implanted sample (b); the $180 \mathrm{keV}, 5 \times 10^{16} \mathrm{Cu}^{+}$ions $/ \mathrm{cm}^{2}, 200 \mathrm{keV}, 5 \times 10^{16}$ $\mathrm{Ag}^{+}$ions $/ \mathrm{cm}^{2}$ sequentially implanted sample (c), and corresponding SAED pattern (d); inset: normalized SRIM simulated distributions of the implanted $\mathrm{Ag}$ ions (solid circle) and the vacancies (open square) in silica produced by implanted $\mathrm{Cu}$ ions

it can be used to tailor the size of NPs without changing their distribution. In order to achieve wide distribution of $\mathrm{Ag}$ NPs, $180 \mathrm{keV} \mathrm{Cu}^{+}$ions were firstly implanted into silica to the fluence of $5 \times 10^{16}$ ions $/ \mathrm{cm}^{2}$, then $200 \mathrm{keV} \mathrm{Ag}{ }^{+}$ions were implanted to the same fluence. It is well known that the nucleation of small metal NPs during ion implantation process firstly occurs at the lower potential energy position, such as defects. Then the later implanted atoms aggregate round the nuclei and the particle grow. The cross-sectional TEM images of $\mathrm{Cu} / \mathrm{Ag}$ sequentially implanted sample is given in Fig. 1(c). For the $\mathrm{Cu}^{+}$ions implanted sample at $180 \mathrm{keV}$ to $5 \times 10^{16}$ ions $/ \mathrm{cm}^{2}$, our previous study showed that the formed $\mathrm{Cu}$ NPs were small due to their compara- 


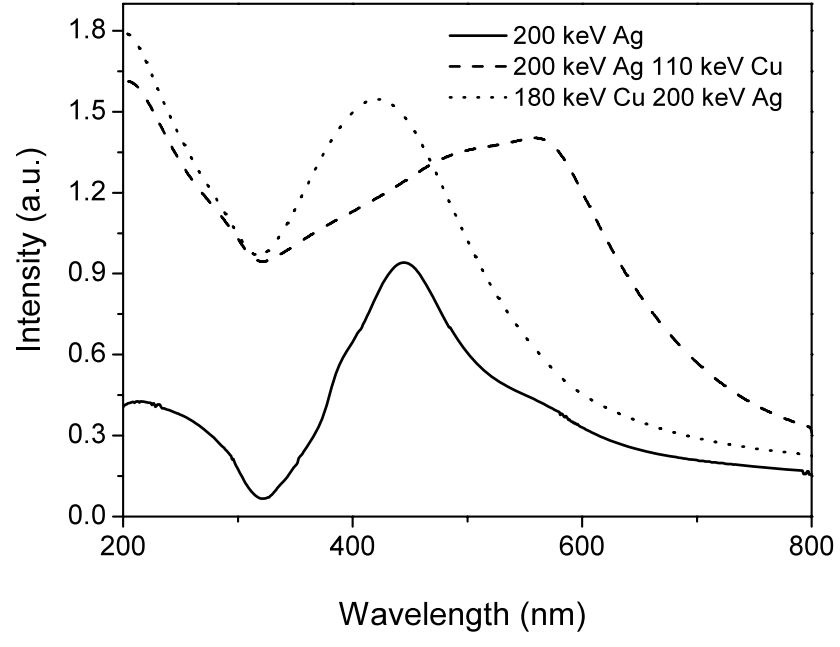

Fig. 2 Optical absorption spectra of the $\mathrm{Ag}, \mathrm{Cu} / \mathrm{Ag}$ and $\mathrm{Ag} / \mathrm{Cu}$ sequentially implanted samples

bly low diffusion coefficient [24]. The selected area electron diffraction pattern of the $\mathrm{Cu} / \mathrm{Ag}$ sequentially implanted sample only shows the obvious diffraction pattern of facecentered cubic (fcc) Ag, which indicates that most of the NPs are Ag NPs. The SRIM 2006 program simulation shows that the distributions of the implanted $\mathrm{Ag}$ ions and the $\mathrm{Cu}$ implantation-induced vacancies in silica are approximately overlapped and the distribution of vacancies is comparably wide (see the insert of Fig. 1(c)). Therefore, the following implanted Ag ions are captured by the defects, which leads to the formation of widely-distributed and uniform Ag NPs. The size distribution of NPs is narrow and the average size is $6.6 \pm 2.0 \mathrm{~nm}$.

Optical absorption spectra of the $\mathrm{Ag}, \mathrm{Ag} / \mathrm{Cu}$ and $\mathrm{Cu} / \mathrm{Ag}$ sequentially implanted samples are presented in Fig. 2. The optical absorption spectrum of $\mathrm{Ag}$ implanted sample is quite different from the Mie resonance absorption spectrum of small NPs in $200 \mathrm{keV} \mathrm{Ag}{ }^{+}$implanted sample to the fluence of $1 \times 10^{16}$ ions $/ \mathrm{cm}^{2}$ [25]. Due to the large size of Ag NPs, multipolar excitation caused by large interaction between $\mathrm{Ag}$ NPs leads to the red shift of SPR peak and the separation of Mie SPR peak to multiple peaks. The SPR peaks of $\mathrm{Ag} / \mathrm{Cu}$ implanted sample is further red-shifted and the intensity increases greatly, which means that the ion implantation of $\mathrm{Cu}$ ions makes the growth of Ag NPs and the interaction between Ag NPs become much more stronger. For the $\mathrm{Cu} / \mathrm{Ag}$ implanted samples, a typical Mie resonance absorption is observed due to their small size $(6.6 \pm 2.0 \mathrm{~nm})$. Moreover, the intensity of plasmon absorption peak increases greatly, which indicates that more $\mathrm{Ag}$ NPs are formed due to the introduction of defects in the substrate.

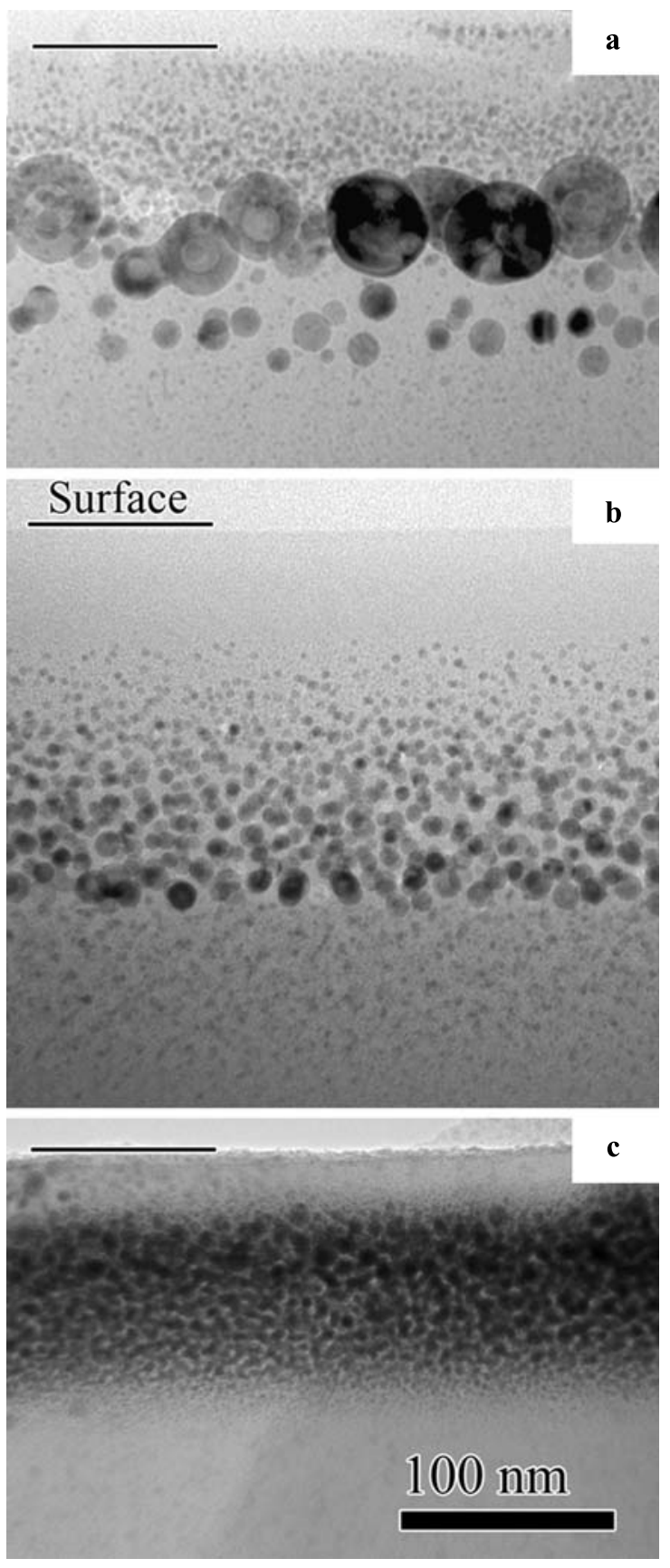

Fig. 3 Cross-sectional TEM images of $200 \mathrm{keV} \mathrm{Ag}^{+}$(a), $180 \mathrm{keV}$ $\mathrm{Cu}^{+}$(b) and $250 \mathrm{keV} \mathrm{Au}{ }^{+}$(c) ions implanted samples to the same fluence of $1 \times 10^{17}$ ions $/ \mathrm{cm}^{2}$

\section{Formation of hollow NPs}

$\mathrm{Ag}, \mathrm{Cu}$ and $\mathrm{Au}$ ions were implanted into silica to the same fluence of $1 \times 10^{17}$ ions $/ \mathrm{cm}^{2}$ at energies of 200,180 , and 250 , respectively. Figure 3(a-c) shows the cross-sectional TEM images of the implanted samples. Hollow Ag and $\mathrm{Cu}$ NPs were formed and the size of nanovoids in $\mathrm{Ag}$ NPs is much larger than that in $\mathrm{Cu}$ NPs. The formation of nanovoids in NPs is due to the aggregation of vacancies. 


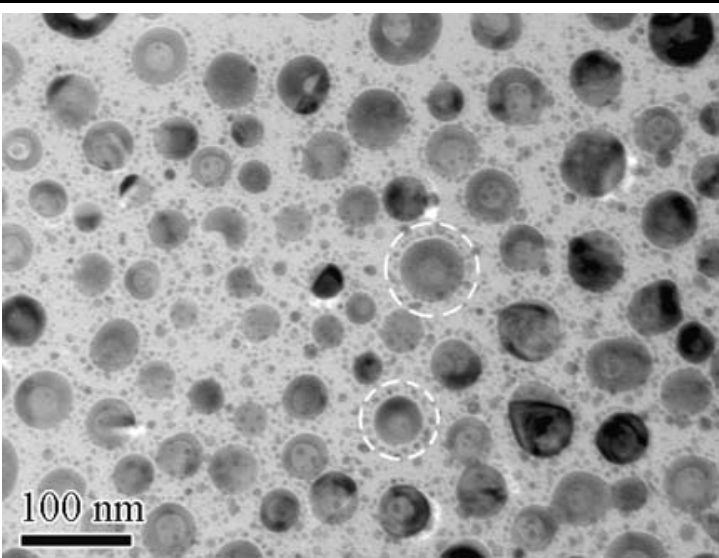

Fig. 4 Planar view TEM image of the $200 \mathrm{keV}, 1 \times 10^{17} \mathrm{Ag}^{+}$ions $/ \mathrm{cm}^{2}$ implanted sample

For the high-fluence ion implantation, the initially formed NPs were irradiated by subsequently implanted high-energy self-ions, knocking out atoms from the NPs and left vacancies. For nano-scaled particles in silica, it is easy to reach high-density vacancies under high-fluence of ion irradiation, because the energy barrier for the diffusion of a neutral vacancy in silica is much higher than that in metal $[26,27]$ and they do not easily diffuse into the surrounding amorphous matrix. When the density of vacancies reaches supersaturation, these vacancies aggregate into nanovoids driven by the heat produced by the collision cascades. The atoms ejected from NP during the ballistic process induced by the collision cascades are separated around the large NPs, and aggregate into small satellite NPs again, as shown in Fig. 4. The formation of satellite NPs were also observed by Mattei et al. by irradiation of $\mathrm{AuCu}$ or AuAg alloy NPs using different ions [28]. They found that the satellite NP size initially increased with the fluence and then tended to be saturated at larger fluences. Moreover, both satellite NP sizes and their distance to the large NP surface have a linear increase with the nuclear energy loss of the irradiating ions. The formation of hollow nanoparticles were also observed in $\mathrm{Fe}[29]$ and $\mathrm{Ag} / \mathrm{Cd}[30], \mathrm{Co} / \mathrm{Ni}(\mathrm{Cu} / \mathrm{Ni})$ [31], $\mathrm{Al} / \mathrm{Fe}(\mathrm{Fe} / \mathrm{Al})$ [32], $\mathrm{Pd} / \mathrm{Ag}(\mathrm{Pd} / \mathrm{Fe})$ [33], and $\mathrm{Fe} / \mathrm{Pt}$ [34] sequentially implanted samples with ion energies around $100 \mathrm{keV}$.

No hollow Au NP is observed in the Au ion implanted sample. To study the influence factors on the formation of nanovoid, $\mathrm{Ag}$ NPs were irradiated by $\mathrm{N}^{+}, \mathrm{Si}^{+}, \mathrm{Ar}^{+}$, $\mathrm{Cu}^{+}$ions at $300 \mathrm{keV}$ to the fluence of $5 \times 10^{16}$ ions $/ \mathrm{cm}^{2}$, and by $\mathrm{Cu}^{+}$ion at energies from 110 to $500 \mathrm{keV}$ to $5 \times$ $10^{16}$ ions $/ \mathrm{cm}^{2}$ [35]. TEM analysis shows that the sizes of nanovoids increase with increasing ion mass, as is shown in Fig. 5(a). The size of the nanovoids also increases with increasing irradiation ion energy, but it reaches saturation at the irradiation ion energy of $400 \mathrm{keV}$ (Fig. 5(b)). Further
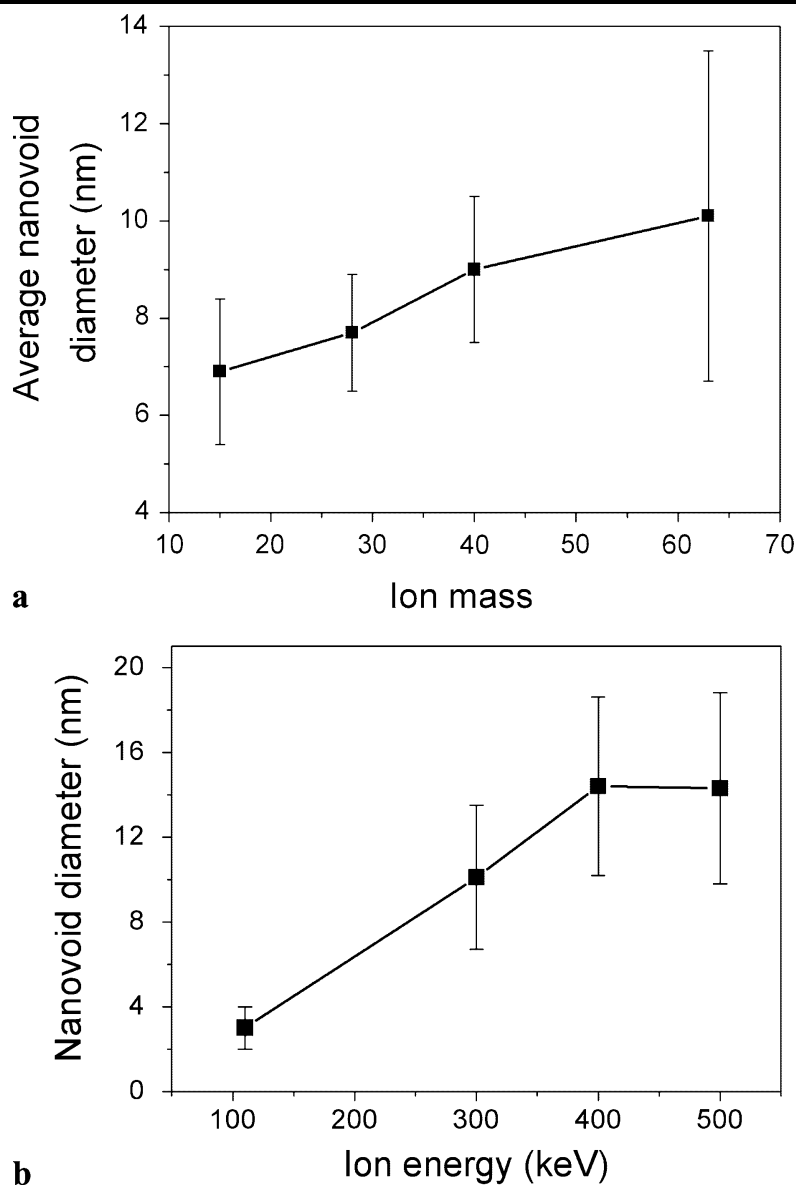

Fig. 5 Relationship between nanovoid size with irradiation ion mass (a), and nanovoid size with irradiation ion energy (b)

analysis indicates that the size of the nanovoids depends on both nuclear and electronic energy losses of the irradiation ions $\left(S_{e}\right.$ and $\left.S_{n}\right)$ : the former produces vacancies and the latter deposits heat to improve the aggregation of vacancies. For the same ion energy, the $S_{n}$ value is improved with increasing ion mass and more vacancies are created during the collision cascades. While for the same ion irradiation, the increase in ion energy causes an increase in $S_{e}$ and more heat is deposited.

The diffusion coefficient of implanted ions also has important influence on the formation of vacancy. If the implanted element has high diffusion coefficient, it is easier to aggregate larger NPs, which means that they have more chance to be irradiated and produce more vacancies. Moreover, the vacancies are easier to move by exchanging vacancies with Ag atoms and aggregate into nanovoids in NPs. This is the reason why the nanovoid size in Ag NPs is usually larger than that in $\mathrm{Cu}$ NPs. No nanovoid is observed in $160 \mathrm{keV}, 2 \times 10^{17} \mathrm{Zn}^{+}$ions $/ \mathrm{cm}^{2}$ implanted sample [36]. A possible reason is that the produced vacancies during the process of collision cascade may possibly be filled quickly due to the low melt point of $\mathrm{Zn}$. 

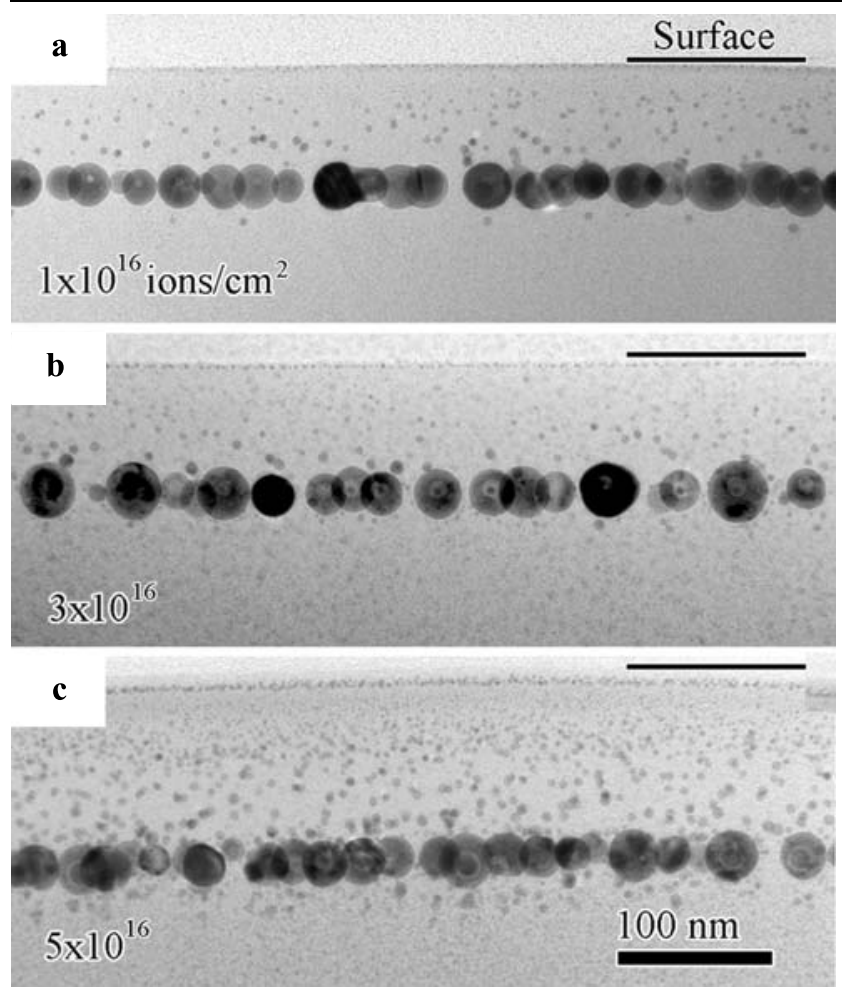

Fig. 6 Cross-sectional TEM images of the $200 \mathrm{keV}, 5 \times 10^{16}$ $\mathrm{Ag}^{+}$ions $/ \mathrm{cm}^{2}$ implanted samples irradiated by $\mathrm{Cu}^{+}$ions at $400 \mathrm{keV}$ to the fluences of $1 \times 10^{16}(\mathbf{a}), 3 \times 10^{16}(\mathbf{b})$, and $5 \times 10^{16}$ ions $/ \mathrm{cm}^{2}(\mathbf{c})$

\section{Formation of sandwiched NPs}

$200 \mathrm{keV} \mathrm{Ag}^{+}$ions were implanted into silica to the fluence of $2 \times 10^{17}$ ions $/ \mathrm{cm}^{2}$. It is very interesting to observe Agnanovoid-Ag sandwiched NPs [37]. $\mathrm{Au}-\mathrm{Fe}_{2} \mathrm{O}_{3}, \mathrm{Fe}-\mathrm{Fe}_{3} \mathrm{O}_{4}$ sandwiched NPs were formed by chemical methods due to the Kirkendall effect [38-40]. How do the sandwiched NPs form in high-fluence implanted samples? Ion irradiation was used to recur the formation process of sandwiched NPs. Solid Ag NPs formed by $200 \mathrm{keV}, 5 \times 10^{16} \mathrm{Ag}^{+}$ions $/ \mathrm{cm}^{2}$ implantation were irradiated by $\mathrm{Cu}^{+}$ions at $400 \mathrm{keV}$ to the fluences of $1 \times 10^{16}, 3 \times 10^{16}, 5 \times 10^{16} \mathrm{ions} / \mathrm{cm}^{2}$. Figure 6 shows the cross-sectional TEM images of the irradiated samples. Firstly, small nanovoids are formed in the $1 \times 10^{16} \mathrm{Cu}^{+}$ions $/ \mathrm{cm}^{2}$ irradiated Ag NPs. Then, these nanovoids grow from $6.3 \pm 2.1 \mathrm{~nm}$ to $11.8 \pm 2.2 \mathrm{~nm}$ with the increase of the irradiation fluence to $3 \times 10^{16}$ ions $/ \mathrm{cm}^{2}$. Small NPs also appear in the nanovoids. Continued irradiation to the fluence of $5 \times 10^{16}$ ions $/ \mathrm{cm}^{2}$ bring about increases in the size of nanovoids to $14.2 \pm 4.2 \mathrm{~nm}$ and the size of inner NPs to $10.4 \pm 3.4 \mathrm{~nm}$. The formation mechanism for the ion implantation and ion irradiation-induced sandwiched NPs can be explained as follows. The irradiation ions interact with the Ag NPs producing collision cascades. Partial $\mathrm{Ag}$ atoms are knocked out from the nanoshells and enter into the nanovoids. Some of the ejected atoms or irradiation

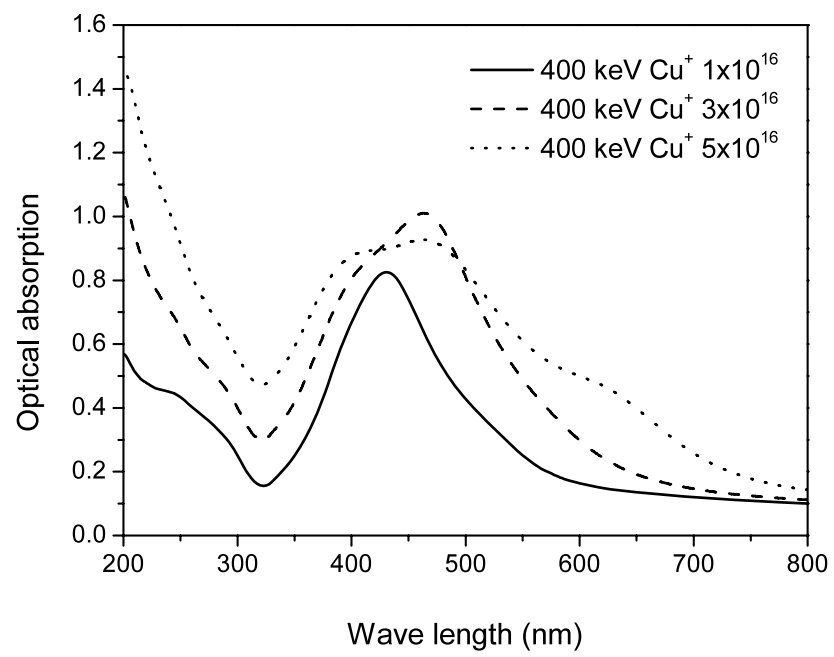

Fig. 7 Optical absorption spectra of the $200 \mathrm{keV}, 5 \times 10^{16}$ $\mathrm{Ag}^{+}$ions $/ \mathrm{cm}^{2}$ implanted samples irradiated by $\mathrm{Cu}^{+}$ions at $400 \mathrm{keV}$ to the fluences of $1 \times 10^{16}, 3 \times 10^{16}$, and $5 \times 10^{16} \mathrm{ions} / \mathrm{cm}^{2}$

ions with suitable energy are captured by the nanoshells and aggregate into inner NPs, while the other ejected Ag atoms are absorbed by the nanoshells or pass though them. With the increase of irradiation fluence, more ejected $\mathrm{Ag}$ atoms are captured by inner NPs and their sizes are increased.

Figure 7(a) is the optical absorption spectra of the Ag implanted samples irradiated by $\mathrm{Cu}^{+}$ions at $400 \mathrm{keV}$ to the fluences of $1 \times 10^{16}, 3 \times 10^{16}$, and $5 \times 10^{16}$ ions $/ \mathrm{cm}^{2}$. After irradiation, the absorption peaks are widened. Although the optical absorption spectrum of NPs composite depends on many factors [41], the change of spectra of the irradiated samples is mainly caused by the change of their morphology, because the TEM analysis shows that the size of Ag NPs changes little after irradiation.

\section{Stability of the hollow and sandwiched NPs}

To study the stability of hollow and sandwiched NPs, the implanted samples were thermally annealed in traditional furnace, TEM or irradiated by electron beam. The $180 \mathrm{keV}$, $2 \times 10^{17} \mathrm{Cu}^{+}$ions $/ \mathrm{cm}^{2}$ implanted samples were annealed at $900^{\circ} \mathrm{C}$ in a reducing atmosphere $\left(5 \% \mathrm{H}_{2}+95 \% \mathrm{Ar}\right)$ for 1 and 4 hours. As shown in Fig. 8, the cross-sectional TEM images clearly reveal the nanovoid growth after annealing for 1 hour. However, when the annealing time reaches 4 hours, the nanovoids disappear. The evolution of nanovoids during the annealing has two stages: growing stage and shrinking stage. In the first stage, irradiationinduced vacancies diffuse in the NPs and aggregate into nanovoids or are absorbed by former existing nanovoids to form the larger ones. This process is similar to the growth of NPs during annealing, which is called the Oswald ripening. When the density of vacancies decreases to a critical value, 
Fig. 8 Cross-sectional TEM images of the $180 \mathrm{keV}, 2 \times 10^{17}$ $\mathrm{Cu}^{+}$ions $/ \mathrm{cm}^{2}$ implanted sample (a) and the sample annealed at $900^{\circ} \mathrm{C}$ in a reducing atmosphere for 1 (b) and 4 (c) hours
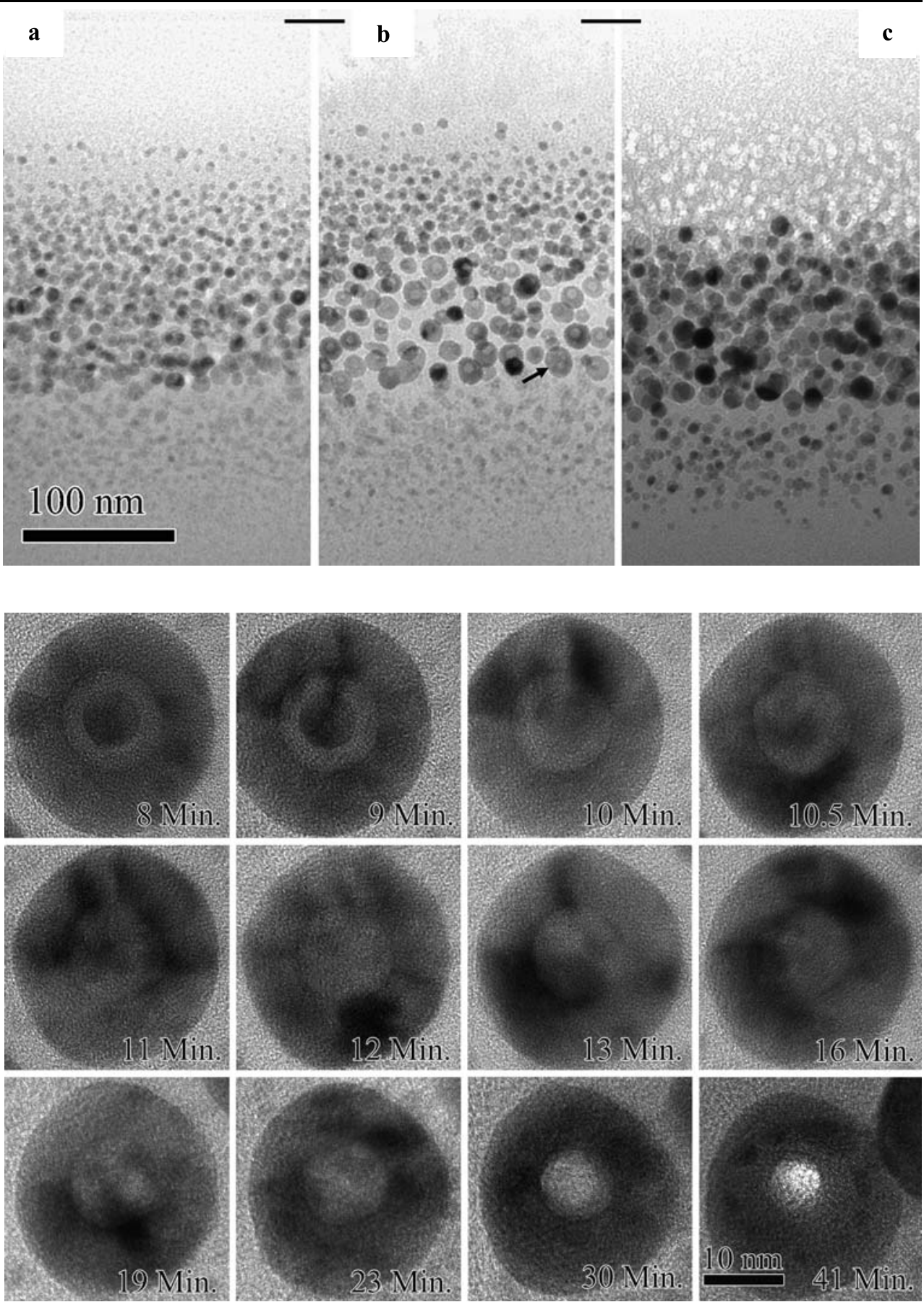

the shrinking stage begins. The shrinkage of nanovoids is due to the absorption of atoms by the inner free surfaces of the nanoshells with dangling bonds. Nanovoids are efficient sites for trapping atoms. Actually, the aggregation of vacancies and capture of Ag atoms take place simultaneously. The size of nanovoid is determined by these completive factors. At the initial stage of annealing, the aggregation of vacancies played a decisive role to form larger nanovoids. Later, the trapping of $\mathrm{Cu}$ atoms became dominant. The growth and shrinkage of nanovoid also appear in the process of ion im- plantation. For the $200 \mathrm{keV} \mathrm{Ag}^{+}$ion implanted samples, when the fluence was $1 \times 10^{17}$ ions $/ \mathrm{cm}^{2}$, the average size of nanovoid was $18.7 \pm 3.6 \mathrm{~nm}$. However, the size decreased to $11.2 \pm 4.2 \mathrm{~nm}$ for the fluence increased to $2 \times 10^{17} \mathrm{ions} / \mathrm{cm}^{2}$ [37].

The evolution of sandwiched NPs under electron beam irradiation is studied by in situ TEM experiment. The irradiation is carried out in a JEOL 2010FEF (UHR) TEM equipped with field emission gun, a Gatan 794 Multi-Scan CCD camera and operated at $200 \mathrm{keV}$. Figure 9 presents the 
Fig. 10 Cross-sectional TEM image of the $200 \mathrm{keV}, 5 \times 10^{16}$ $\mathrm{Ag}^{+}$ions $/ \mathrm{cm}^{2}$ implanted sample followed by implantation of $200 \mathrm{keV}, 5 \times 10^{16} \mathrm{Ar}^{+}$ ions $/ \mathrm{cm}^{2}(\mathbf{a})$, and the sample irradiated by e-beam $(\mathbf{b}-\mathbf{i})$

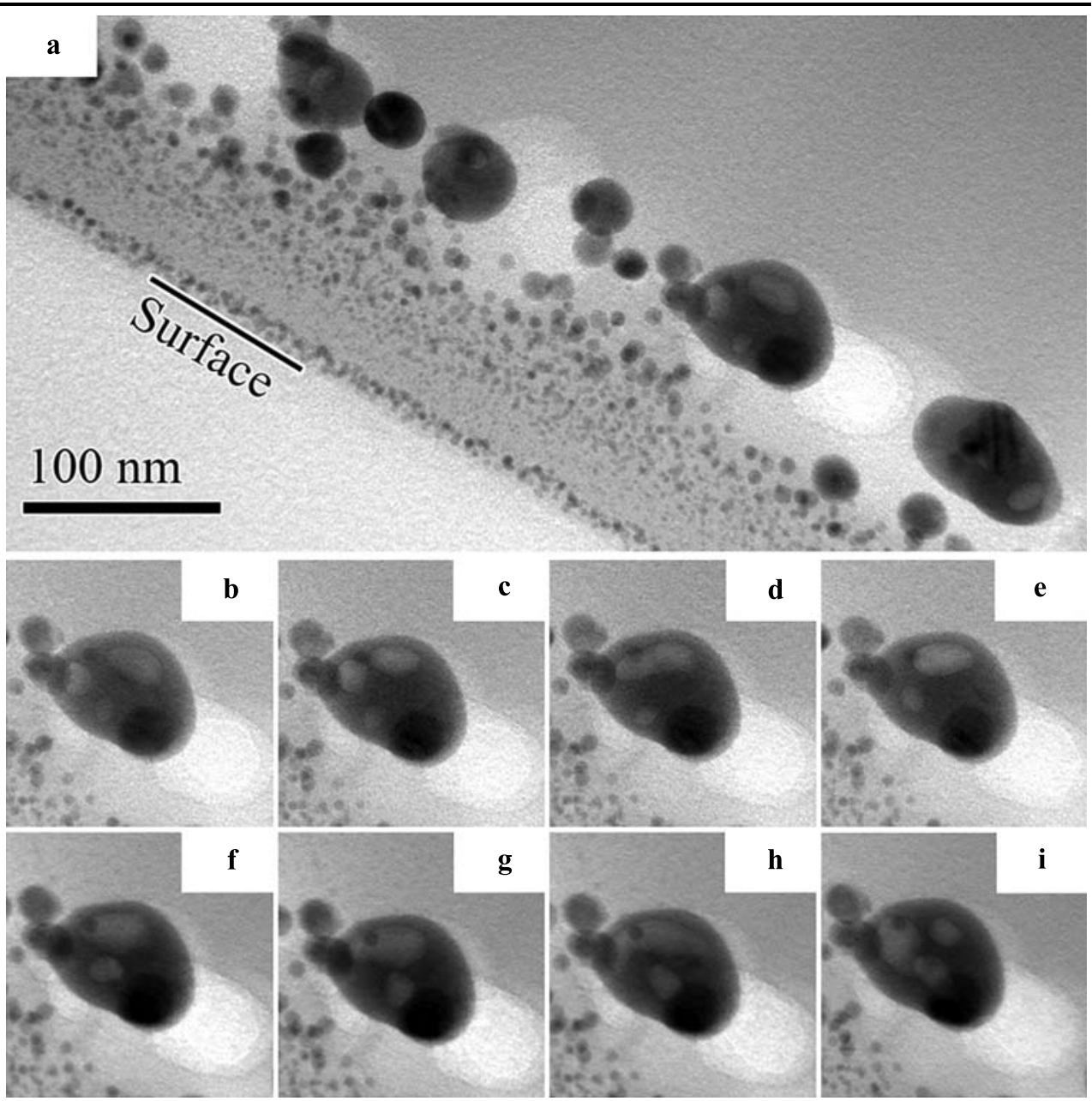

HRTEM images of a sandwiched NP irradiated by e-beam for different times. For the e-beam irradiation, the e-beam was converged to about $40 \mathrm{~nm}$. During the image acquirement, the e-beam was dispersed. The sandwiched NP was stable during the first 9 minutes of irradiation. After that, the inner NP rapidly became smaller and disappeared finally. We suggest that there are two important effects in the process of e-beam irradiation. One is the irradiationinduced heat effect, which can improve atomic diffusion. The heat is produced due to the electron interaction between the incident electronic beam and the electrons in irradiated atoms (inelastic scattering) [42]. Another effect is the electron knock-on effect. The elastic collision between incident electron and nuclei of irradiated atoms can make the displacement of atoms if the energy of electron is high enough, which will lead to producing of defects in material or even amorphization of the material. Although the reported threshold acceleration voltage for noble crystalline metal is high, $400 \mathrm{keV}$ for $\mathrm{Cu}$ [43] and $800 \mathrm{keV}$ [44] for $\mathrm{Ag}$, the irradiation makes the image of the inner NP obscure. The threshold accelerations for silicon and oxygen are relatively low. Thus, the drilling effect [45] appears after the long irradia- tion time, for 31 minutes. The thickness of silica decreases, which makes more bright contrast in the irradiated region. The irradiation-induced heating effect should be the main reason that makes the evolution of the sandwiched NP. The converged e-beam irradiation will produce thermal spikes for energy transfer from the electron beam to the NP and will cause great local temperature increasing after the long time irradiation [46]. The inner NP disappeared completely after irradiation of 13 minutes. With the increase of irradiation time, the nanovoid was shrunk and the size changed from 14 to $6 \mathrm{~nm}$ after irradiation. Similar behavior of sandwiched NP was observed by in situ TEM annealing at $600^{\circ} \mathrm{C}$ [37].

In order to observe the behavior difference between an NP containing nanovoid and an NP containing insert gas bubble, the latter was irradiated by e-beam and observed by in situ TEM. The Ar nanobubble-containing Ag NPs was formed by $\mathrm{Ag} / \mathrm{Ar}$ sequential ion implantation at the same ion energy of $200 \mathrm{keV}$ to the same fluence of $5 \times 10^{16} \mathrm{ions} / \mathrm{cm}^{2}$. Figure 10(a) shows the cross-sectional TEM image of the sequential implanted sample. Obviously, large Ar nanobubbles are formed in silica due to the high-fluence Ar ion im- 
Fig. 11 TEM image of the $200 \mathrm{keV}, 2 \times 10^{17}$

$\mathrm{Ag}^{+}$ions $/ \mathrm{cm}^{2}$ implanted sample dissolved in 5\% $\mathrm{HF}$ acid for 30 minutes and 24 hours
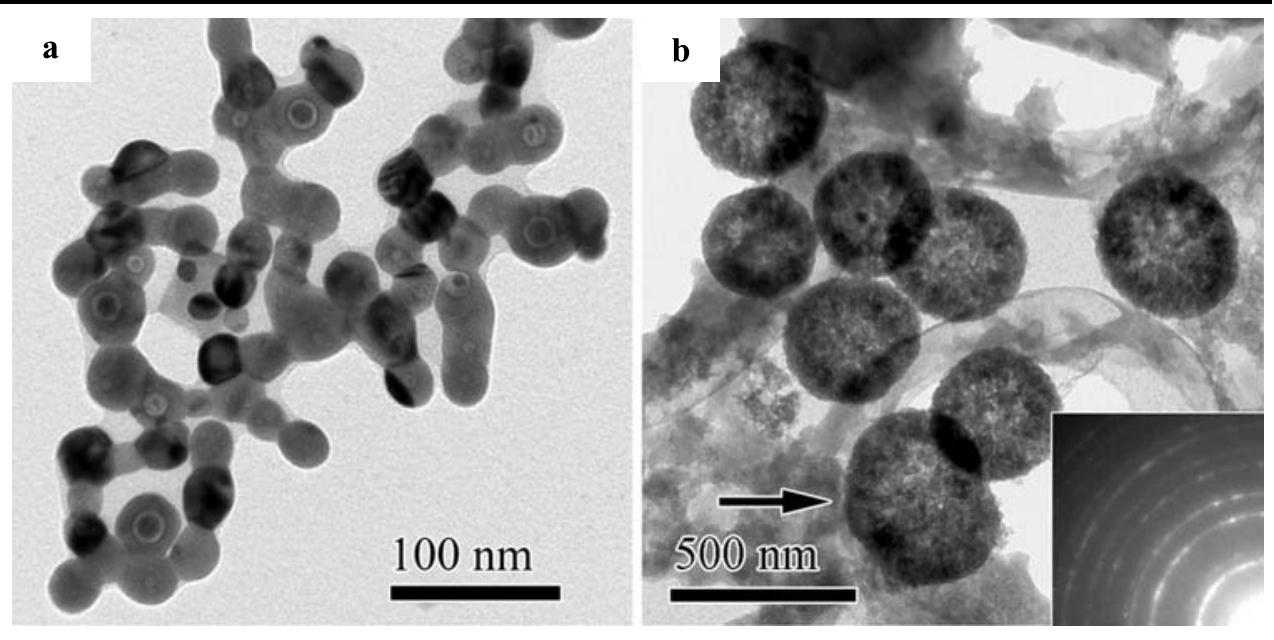

plantation and aggregation of Ar atoms at the damage region. Argon nanobubbles are also formed in Ag NPs because nanovoids are a good container for gas. The e-beam irradiation was carried out in a JEOL 2010 (HT) TEM equipped with $\mathrm{LaB}_{6}$ electron gun and Gatan 780 dual-view CCD camera. The e-beam was converged to about $400 \mathrm{~nm}$ in diameter for irradiation. Figure 10(b-e) shows the evolution of three Ar nanobubbles under e-beam irradiation. Clearly, two large nanobubbles are moving closer and incorporate into one. However, when the e-beam was converged a little smaller, the incorporated nanobubble could be separated into two (Fig. 10(f-i)). The movement of nanobubble is caused by the heating effect of e-beam irradiation. The moving speed depends on the size of nanobubble and the current density of e-beam. When the e-beam was converged smaller further (about $100 \mathrm{~nm}$ ), the nanobubbles were separated into many small ones and "running" very fast in Ag NP, just like the movement of bubbles in boiling water.

Although the hollow and sandwiched NPs change under electron irradiation or thermal annealing, they are very stable at room temperature or at normal TEM observation, because they are well protected by surrounding substrate. Without the protection of substrate, they become unstable. Figure 11 $(a, b)$ shows the TEM images of NPs in the $200 \mathrm{keV}, 2 \times 10^{17} \mathrm{Ag}^{+}$ions $/ \mathrm{cm}^{2}$ implanted sample eroded by $5 \% \mathrm{HF}$ acid for 30 minutes and 24 hours. After the silica was eroded, the coalescence of Ag NPs began to and finally formed large hollow NPs. The selected area electron diffraction of these hollow NPs (the insert image) shows the FCC structure of Ag. In a word, no mater what diverse phenomena appear during the evolution of hollow or sandwiched NPs, there is a fundamental physics: the NP system tends to reduce its energy. Vacancies and nanovoids containing NP are metastable and have high surface energy for the nanometer-curved surface-atom dangling-bond structure. They tend to transform to more stable state.

\section{Conclusions}

In conclusion, ion beam technology provides a versatile method to tailor the size, distribution and morphology of NP by precise selecting of the experimental conditions. Sequential ion implantation was used to control the size and distribution of Ag NPs. Hollow and sandwiched Ag NPs were formed by high-fluence ion implantation and ion irradiation. The influence factors for the formation of hollow and sandwiched NPs were released. Thermal annealing, electron beam and chemical erosion of hollow and sandwiched NPs show that these NPs are in metastable and they also trend to transform to more stable states.

Acknowledgements This work was partially supported by the National Natural Science Foundation of China (Nos. 10435060 and 10775109), by the Specialized Research Fund for the Doctoral Program of Higher Education (Nos. 20050486054, 20070486069), and by Young Chenguang Project of Wuhan City (No. 200850731371).

Open Access This article is distributed under the terms of the Creative Commons Attribution Noncommercial License which permits any noncommercial use, distribution, and reproduction in any medium, provided the original author(s) and source are credited.

\section{References}

1. J. Aizpurua, R. Guckenberger, R. Hillenbrand, Phys. Rev. Lett. 97, 060801 (2006)

2. Y.H. Wang, C.Z. Jiang, F. Ren, Q.Q. Wang, D.J. Chen, D.J. Fu, Phys. Lett. A 357, 364 (2006)

3. D. Peer, J.M. Karp, S. Hong, O.C. Farokhzad, R. Margali, R. Langer, Nat. Nanotechnol. 2, 751 (2007)

4. A.M. Gobin, M.H. Lee, N.J. Halas, W.D. James, R.A. Drezek, J.L. West, Nano Lett. 7, 1929 (2007)

5. S.A. Maier, P.G. Kik, H.A. Atwater, S. Meltzer, E. Harel, B.E. Koel, A.A.G. Requicha, Nat. Mater. 2, 229 (2003)

6. W. Zhang, P.C. Mathias, E. Chow, J.A.N.T. Soares, V. Malyarchuk, A.D. Smith, B.T. Cunningham, Nat. Nanotechnol. 2, 515 (2007)

7. Y.G. Sun, Y.N. Xia, Science 298, 2176 (2002) 
8. S. Dhara, Crit. Rev. Solid State 32, 1 (2007)

9. A. Meldrum, L.A. Boatner, C.W. White, Nucl. Instrum. Methods Phys. Res., Sect. B 178, 7 (2001)

10. G. De Marchi, G. Mattei, P. Mazzoldi, C. Sada, J. Appl. Phys. 92, 4249 (2002)

11. R. Giulian, P. Kluth, D.J. Sprouster, L.L. Araujo, A. Byrne, M.C. Ridgway, Nucl. Instrum. Methods Phys. Res., Sect. B 266, 3158 (2008)

12. A. Oliver, J.A. Reyes-Esqueda, J.C. Cheang-Wong, C.E. RománVelázquez, A. Crespo-Sosa, L. Rodríguez-Fernández, J.A. Seman, C. Noguez, Phys. Rev. B 74, 245425 (2006)

13. J.J. Penninkhof, A. Polman, L.A. Sweatlock, S.A. Maier, H.A. Atwater, A.M. Vredenberg, B.J. Kooi, Appl. Phys. Lett. 83, 4137 (2003)

14. E.M. Bringa, R.E. Johnson, Phys. Rev. Lett. 88, 165501 (2002)

15. H. Trinkaus, A.I. Ryazanov, Phys. Rev. Lett. 74, 5072 (1995)

16. S. Klaumunzer, Nucl. Instrum. Methods B 215, 345 (2004)

17. M. Toulemonde, C. Dufour, E. Paumier, Acta Phys. Pol. A 109, 311 (2006)

18. G. Rizza, H. Cheverry, T. Gacoin, A. Lamasson, S. Henry, J. Appl. Phys. 101, 014321 (2007)

19. P. Kluth, B. Johannessen, G.J. Foran, D.J. Cookson, S.M. Kluth, M.C. Ridgway, Phys. Rev. B 74, 014202 (2006)

20. V. Ramaswamy, T.E. Haynes, C.W. White, W.J. MoberlyChan, S. Roorda, M.J. Aziz, Nano Lett. 5, 373 (2005)

21. G.X. Cai, F. Ren, X.H. Xiao, L.X. Fan, C.Z. Jiang, Nucl. Instrum. Methods B 266, 889 (2008)

22. A.L. Stepanov, V.N. Popok, Surf. Sci. 566, 1250 (2004)

23. N. Kishimoto, O.A. Plaksin, N. Umeda, Y. Takeda, Nucl. Instrum. Methods Phys. Res., Sect. B 219, 810 (2004)

24. F. Ren, C.Z. Jiang, C. Liu, J.B. Wang, Appl. Phys. Lett. 88, 183114 (2006)

25. F. Ren, C.Z. Jiang, D.J. Fu, Q. Fu, Jpn. J. Appl. Phys. 44, 8512 (2005)

26. G. De Lorenzi, F. Ercolessi, Europhys. Lett. 20, 349 (1992)

27. J.Y. Song, L.R. Corrales, G. Kresse, H. Jónsson, Phys. Rev. B 64, $134102(2001)$

28. V. Bello, G. De Marchi, C. Maurizio, G. Mattei, P. Mazzoldi, M. Parolin, C. Sada, J. Non-Cryst. Sol. 345-346, 685 (2004)

29. K.S. Buchanan, A. Krichevsky, M.R. Freeman, A. Meldrum, Phys. Rev. B 70, 174436 (2004)
30. T.S. Anderson, R.H. Magruder III, D.L. Kinser, J.E. Wittig, R.A. Zuhr, D.K. Thomas, J. Non-Cryst. Sol. 224, 299 (1998)

31. C. de Julián Fernández, C. Sangregorio, G. Mattei, C. Maurizio, G. Battaglin, F. Gonella, A. Lascialfari, S. Lo Russo, D. Gatteschi, P. Mazzoldi, J.M. Gonzalez, F. D’Acapito, Nucl. Instrum. Methods Phys. Res., Sect. B 175, 479 (2001)

32. C. de Julián Fernández, M.A. Tagliente, G. Mattei, C. Sada, V. Bello, C. Maurizio, G. Battaglin, C. Sangregorio, D. Gatteschi, L. Tapfer, P. Mazzoldi, Nucl. Instrum. Methods Phys. Res., Sect. B 216, 245 (2004)

33. G. Mattei, G. Battaglin, V. Bello, E. Cattaruzza, C. De Julian, G. De Marchi, C. Maurizio, P. Mazzoldi, M. Parolin, C. Sada, Nucl. Instrum. Methods Phys. Res., Sect. B 218, 433 (2004)

34. C.W. White, S.P. Withrow, J.D. Budai, L.A. Boatner, K.D. Sorge, J.R. Thompson, K.S. Beaty, A. Meldrum, Nucl. Instrum. Methods Phys. Res., Sect. B 191, 437 (2002)

35. F. Ren, G.X. Cai, X.H. Xiao, L.X. Fan, C. Liu, D.J. Fu, J.B. Wang, C.Z. Jiang, J. Appl. Phys. 103, 084308 (2008)

36. F. Ren, L.P. Guo, Y. Shi, D.L. Chen, Z.Y. Wu, C.Z. Jiang, J. Phys. D, Appl. Phys. 39, 488 (2006)

37. F. Ren, C.Z. Jiang, C. Liu, J.B. Wang, T. Oku, Phys. Rev. Lett. 97, 165501 (2006)

38. E.V. Shevchenko, M.I. Bodnarchuk, M.V. Kovalenko, D.V. Talapin, R.K. Smith, S. Aloni, W. Heiss, A. Paul Alivisatos, Adv. Mater. 9999, 1 (2008)

39. S. Peng, C. Wang, J. Xie, S.H. Sun, J. Am. Chem. Soc. 128, 10676 (2006)

40. A. Cabot, V.F. Puntes, E. Shevchenko, Y.D. Yin, L. Balcells, M.A. Marcus, S.M. Hughes, A.P. Alivisatos, J. Am. Chem. Soc. 129, 10358 (2007)

41. F. Ren, C.Z. Jiang, C. Liu, D.J. Fu, Y. Shi, Sol. Stat. Commun. 135, 268 (2005)

42. M. Klimenkov, W. Matz, J.V. Borany, Nucl. Instrum. Methods Phys. Res., Sect. B 168, 367 (2000)

43. T. Nagase, Y. Umakoshi, Sci. Technol. Adv. Mater. 5, 57 (2004)

44. P.G. Lucasson, R.M. Walker, Phys. Rev. 127, 485 (1962)

45. G.S. Chen, C.B. Boothroyd, C.J. Humphreys, Philos. Mag. A 78, 491 (1998)

46. M. Klimenkov, W. Matz, S.A. Nepijko, M. Lehmann, Nucl. Instrum. Methods Phys. Res., Sect. B 179, 209 (2001) 